\title{
How the Starting Precursor Influences the Properties of Polycrystalline CuInGaSe 2 Thin Films Prepared by Sputtering and Selenization
}

\author{
Greta Rosa ${ }^{1, *}$, Alessio Bosio ${ }^{1}$, Daniele Menossi ${ }^{2}$ and Nicola Romeo ${ }^{1}$ \\ 1 Thin Film Laboratory, Department of Physics and Earth Sciences, University of Parma, \\ Parco Area delle Scienze 7/ A, Parma 43124, Italy; alessio.bosio@unipr.it (A.B.); nicola.romeo@unipr.it (N.R.) \\ 2 Computer Science Department, University of Verona, Ca' Vignal 1, Strada Le Grazie 15, Verona 37134, Italy; \\ daniele.menossi@nemo.unipr.it \\ * Correspondence: greta.rosa@difest.unipr.it; Tel.: +39-0521-905257
}

Academic Editor: Jean-Michel Nunzi

Received: 22 January 2016; Accepted: 27 April 2016; Published: 10 May 2016

\begin{abstract}
Cu}(\mathrm{In}, \mathrm{Ga}) \mathrm{Se}_{2}$ (CIGS)/CdS thin-film solar cells have reached, at laboratory scale, an efficiency higher than $22.3 \%$, which is one of the highest efficiencies ever obtained for thin-film solar cells. The research focus has now shifted onto fabrication processes, which have to be easily scalable at an industrial level. For this reason, a process is highlighted here which uses only the sputtering technique for both the absorber preparation and the deposition of all the other materials that make up the cell. Particular emphasis is placed on the comparison between different precursors obtained with either $\mathrm{In}_{2} \mathrm{Se}_{3}$ and $\mathrm{Ga}_{2} \mathrm{Se}_{3}$ or InSe and GaSe as starting materials. In both cases, the precursor does not require any heat treatment, and it is immediately ready to be selenized. The selenization is performed in a pure-selenium atmosphere and only lasts a few minutes at a temperature of about $803 \mathrm{~K}$. Energy conversion efficiencies in the range of $15 \%-16 \%$ are reproducibly obtained on soda-lime glass (SLG) substrates. Similar results are achieved if commercial ceramic tiles are used as a substrate instead of glass. This result is especially useful for the so-called building integrated photovoltaic. $\mathrm{Cu}(\mathrm{In}, \mathrm{Ga}) \mathrm{Se}_{2}$-based solar cells grown directly on ceramic tiles are ideal for the fabrication of ventilated façades in low impact buildings.
\end{abstract}

Keywords: $\mathrm{Cu}(\mathrm{In}, \mathrm{Ga}) \mathrm{Se}_{2}$ (CIGS); thin-film solar cell; sputtering; precursors

\section{Introduction}

The price of photovoltaic (PV) systems has decreased by about $75 \%$ in the last 10 years. Nowadays, PV appears as a cost-competitive, reliable, and sustainable electricity source [1]. Thin-film solar cells are one of the most promising technologies for the production of "clean" and low-cost energy. This is due to a greatly reduced consumption of semiconductor material and to the fact that solar cells can be manufactured on inexpensive large-area substrates. In this way, PV modules with a final cost well below US $\$ 0.50$ per peak Watt (Wp) can be produced.

One of the most promising thin-film solar cells is represented by the $\mathrm{CuIn}_{1-\mathrm{x}} \mathrm{Ga}_{x} \mathrm{Se}_{2}$-based cell because it has a high optical absorption coefficient in the visible part of the solar light and a tunable band gap that varies from $1.04 \mathrm{eV}$ (for $\mathrm{CuInSe}_{2}$ ) to $1.68 \mathrm{eV}$ (for $\mathrm{CuGaSe}_{2}$ ) [2]. $\mathrm{As} \mathrm{Cu}(\mathrm{In}, \mathrm{Ga}) \mathrm{Se}_{2}$ (CIGS)-based solar cells are normally built in substrate configuration, the substrate must not necessarily be transparent, and this device structure makes it possible to use different substrates in addition to the typical soda-lime glass (SLG). CIGS-based devices have been successfully grown on opaque substrates such as ceramic tiles and on flexible substrates such as polymers and thin metal sheets (stainless steel, titanium, tantalum, copper, aluminum, molybdenum) [3,4]. 
Recently, Solar Frontier has announced a record efficiency of $22.3 \%$ on a $0.5 \mathrm{~cm} \times 0.5 \mathrm{~cm}$ CIGS-based cell. This result represents a world record for all thin-film solar cells [5].

Here, we review the latest work performed by our Thin Film Laboratory (ThiFiLab) and, in particular, the comparison between devices obtained with different starting precursors, namely, $\operatorname{In}_{2} \mathrm{Se}_{3}$ and $\mathrm{Ga}_{2} \mathrm{Se}_{3}$ versus InSe and GaSe. In both cases, the precursors are deposited by sputtering and selenized immediately afterward. The selenization stage is performed in a pure Se atmosphere, which makes this technique environmentally sustainable.

The work's main objective is to identify which particular sequences of precursor layers-crucial agents for the formation of a CIGS absorber film-yield the highest value for both solar cell photovoltage and photocurrent. One such sequence of starting layers, which was found to bring about a V-shaped distribution of Ga inside the CuInGaSe 2 film, has been discovered and examined. The following points summarize the benefits of this special Ga distribution:

- The greater the concentration of gallium is, and the larger the gap of $\mathrm{CuInGaSe}_{2}$.

- A high-gap material in the junction region ensures a high built-in potential allowing for greater photovoltage.

- Where the concentration of gallium is lower, the energy gap of the material is also narrower, increasing its ability to absorb photons with longer wavelengths. As a result, a higher photocurrent can be achieved.

- A high-gap material at the back contact could repel the minority carriers back into the grains, increasing their lifetime.

If all these requirements are complied with, the resulting solar cells will exhibit energy conversion efficiencies well above $16 \%$. This process can effectively yield high-efficiency solar cells, and it is easily scalable at an industrial level. The devices fabricated on commercial ceramic tiles obtained similar results, with efficiencies as high as $14 \%$. The PV tiles are particularly suitable for the production of ventilated walls, widely used in the construction of low energy-consumption buildings.

\section{Process Description and Experimental Results}

\subsection{The $\mathrm{In}_{2} \mathrm{Se}_{3}, \mathrm{Ga}_{2} \mathrm{Se}_{3}$, and $\mathrm{Cu}$ System}

The CIGS solar cell fabrication starts with a direct current (DC) magnetron sputtering deposition in an argon atmosphere of amolybdenum back contact on a 4-mm-thick SLG substrate. Then, an $\operatorname{In}_{2} \mathrm{Se}_{3}$, $\mathrm{Ga}_{2} \mathrm{Se}_{3}$, and $\mathrm{Cu}$ sequence is deposited on top of the molybdenum film in the same sputtering chamber without breaking the vacuum [6].

In particular, this process involves a radio frequency (RF) magnetron sputtering deposition of a 1000-nm-thick $\mathrm{In}_{2} \mathrm{Se}_{3}$ film at a substrate temperature of about $670 \mathrm{~K}$, with $3.3 \mathrm{~W} / \mathrm{cm}^{2}$ power density at a deposition rate of $1 \mathrm{~nm} / \mathrm{s}$ under a $0.5 \mathrm{~Pa}$ argon pressure (this deposition rate was measured with a quartz micro-balance, while film thickness was measured with a profilometer) [7]. On top of the $\mathrm{In}_{2} \mathrm{Se}_{3}$ layer, a 330-nm-thick $\mathrm{Ga}_{2} \mathrm{Se}_{3}$ film is deposited by $\mathrm{RF}$ magnetron sputtering, at a substrate temperature of about $720 \mathrm{~K}$, with a $1.8 \mathrm{~W} / \mathrm{cm}^{2}$ power density at a deposition rate of $0.4 \mathrm{~nm} / \mathrm{s}$ under a $0.2 \mathrm{~Pa}$ argon pressure. Immediately after, a 180-nm-thick $\mathrm{Cu}$ film is deposited by d.c. magnetron sputtering, at a substrate temperature of about $620 \mathrm{~K}$, with a $1.8 \mathrm{~W} / \mathrm{cm}^{2}$ power density at a deposition rate of $0.6 \mathrm{~nm} / \mathrm{s}$ under a $0.2 \mathrm{~Pa}$ argon pressure (Figure 1a). The difference between the deposition temperatures of these layers is due to the high reactivity and diffusivity of copper. Its diffusion increases as temperature rises. $\mathrm{Cu}$ reactivity is so strong that it induces surface segregation of secondary phases and partial separation of the crystalline grains, which negatively affect film uniformity. This problem can be avoided by depositing $\mathrm{Cu}$ on top of the $\mathrm{Ga}_{2} \mathrm{Se}_{3}$ film at low substrate temperature ( $\leqslant 620 \mathrm{~K}$ ). By performing a further annealing in vacuum at a temperature of $670 \mathrm{~K}$, a uniform film with enhanced single-phase crystallization is finally obtained. The compositional uniformity of the precursor material allows the 
selenization process, which is performed in a pure-selenium atmosphere for $10 \mathrm{~min}$ at a temperature of about $800 \mathrm{~K}$.

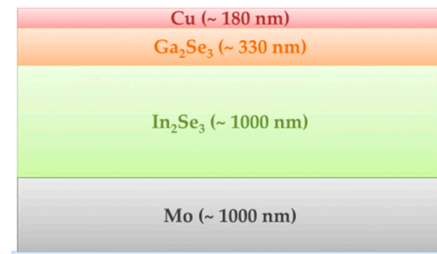

(a)

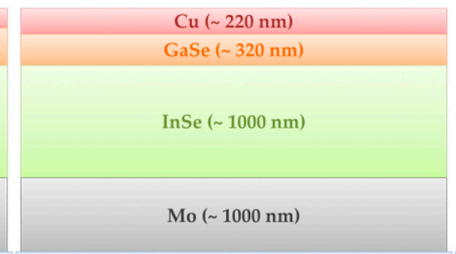

(b)

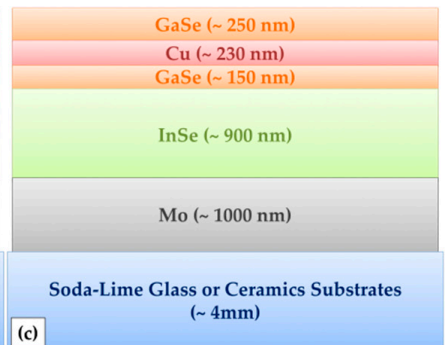

(c)

Figure 1. The different precursor layers and sequences used to obtain the absorber material reviewed in this article: (a) first method: deposition in sequence of $\mathrm{In}_{2} \mathrm{Se}_{3}-\mathrm{Ga}_{2} \mathrm{Se}_{3}-\mathrm{Cu}$; (b) second method: deposition in sequence of InSe-GaSe-Cu; (c) third method: deposition in sequence of InSe-GaSe-Cu-GaSe.

The CIGS absorber material prepared according to this method displays a uniform morphology throughout the whole substrate area, as can be seen in Figures 2 and 3.

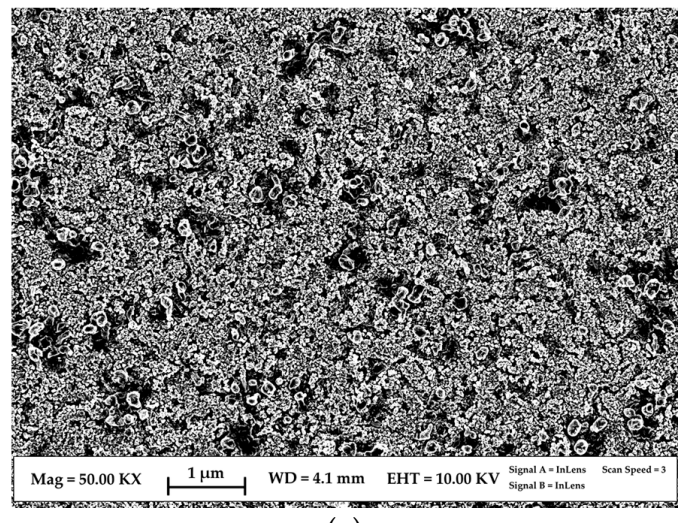

(a)

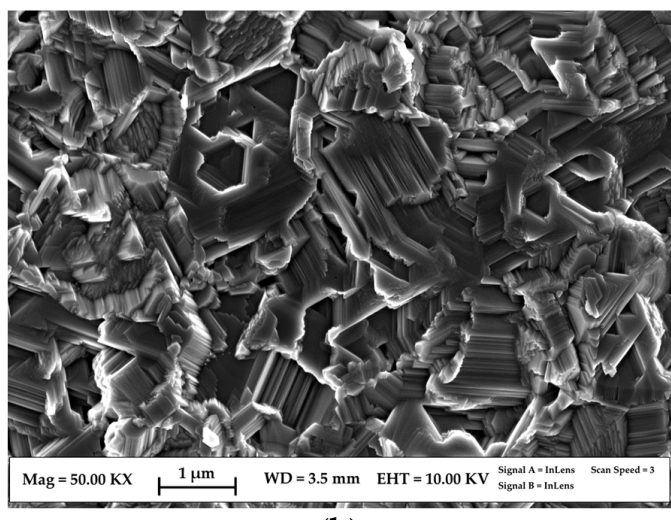

(b)

Figure 2. SEM image of the: (a) morphology of the as-deposited $\mathrm{In}_{2} \mathrm{Se}_{3}-\mathrm{Ga}_{2} \mathrm{Se}_{3}-\mathrm{Cu}$ precursor sequence; and $(\mathbf{b})$ the resulting $\mathrm{Cu}(\mathrm{In}, \mathrm{Ga}) \mathrm{Se}_{2}$ (CIGS) layer after selenization.

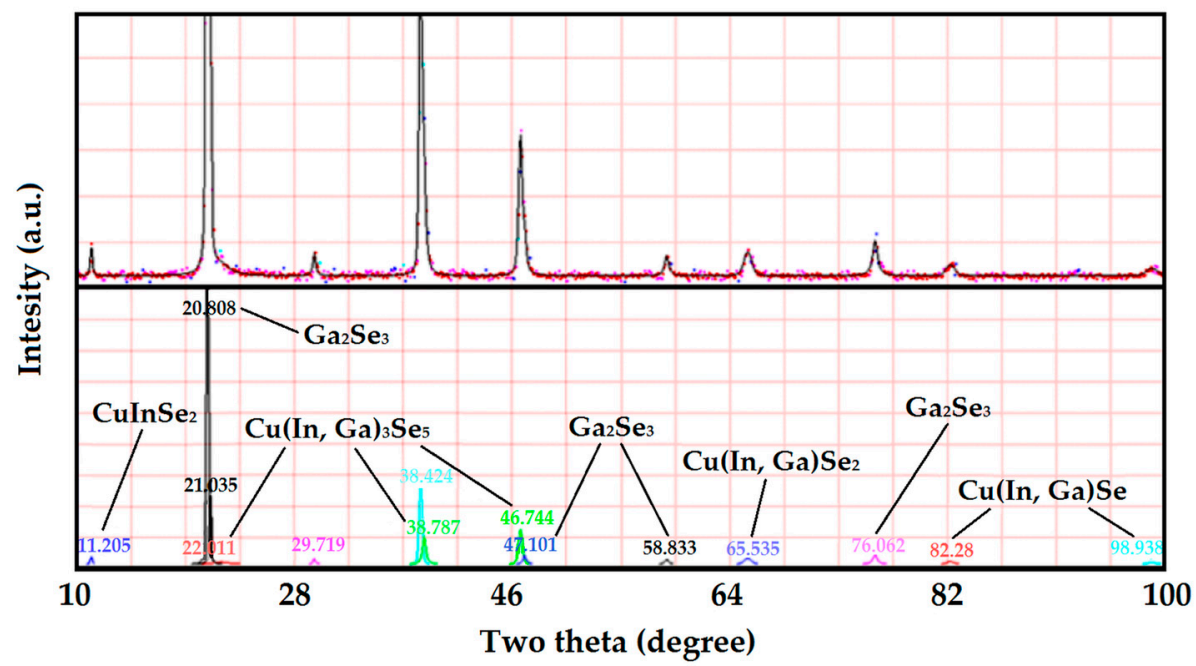

Figure 3. X-ray diffraction (XRD) spectrum of the CIGS layer after selenization, obtained using $\operatorname{In}_{2} \mathrm{Se}_{3}$, $\mathrm{Ga}_{2} \mathrm{Se}_{3}$, and $\mathrm{Cu}$ as starting materials. 
This material can be obtained with a similar morphology and composition even when a vacuum annealing is not performed before the selenization stage with the great benefit of a strong reduction in the process time. The highest photovoltaic parameters exhibited by solar cells produced with this absorber material are the following: open-circuit voltage $\mathrm{V}_{\mathrm{OC}}=530 \mathrm{mV}$, short-circuit current density JSC $=35.16 \mathrm{~mA} / \mathrm{cm}^{2}$, fill-factor $\mathrm{FF}=58 \%$, and efficiency $\eta=10.81 \%$. Measurements were performed at 298 $\mathrm{K}$ under $100 \mathrm{~mW} / \mathrm{cm}^{2}$ air mass (A.M.) 1.5 filtered light (standard conditions) (Current Density-Voltage (J-V) curve in Figure A1, sample \#2012). It is possible, in these thermodynamic conditions, that a $\mathrm{CuInSe}_{2}$ (CIS) matrix with a more ideal crystal structure can form, preventing the lattice defects from trapping the photo-generated carriers and allowing them to be collected and transported more effectively through the junction.

In order to obtain CIGS-based solar cells of higher efficiency, a proper distribution of a Ga concentration within the absorber material is needed. In particular, an accurately tailored double-graded $\mathrm{Ga}$ concentration may allow for the engineering of a specific energy gap $\left(\mathrm{E}_{\mathrm{G}}\right)$ design (Figure 4). If this design is followed, a back grading will provide an additional drift field for the minority electrons, and this will in turn improve carrier collection and reduce back-contact recombination [8-10]. A second Ga grading will appear near the CIGS/CdS interface where the Ga concentration will be made higher towards the $p$ - $n$ junction. This superficial grading region must be kept thin enough, well below $20 \mathrm{~nm}$, to let carriers overcome this barrier or pass through it by a tunnel mechanism. This makes it possible to increase the $\mathrm{V}_{\mathrm{OC}}$. In order to increase, as much as possible, the amount of solar photons absorbed inside the space charge region, a low $\mathrm{E}_{\mathrm{G}}$ layer has to be produced inside the absorber. This layer, with a thickness of about $1000 \mathrm{~nm}$, can increase the long wavelength absorption and thus supply a higher amount of photo-generated carriers [11,12].

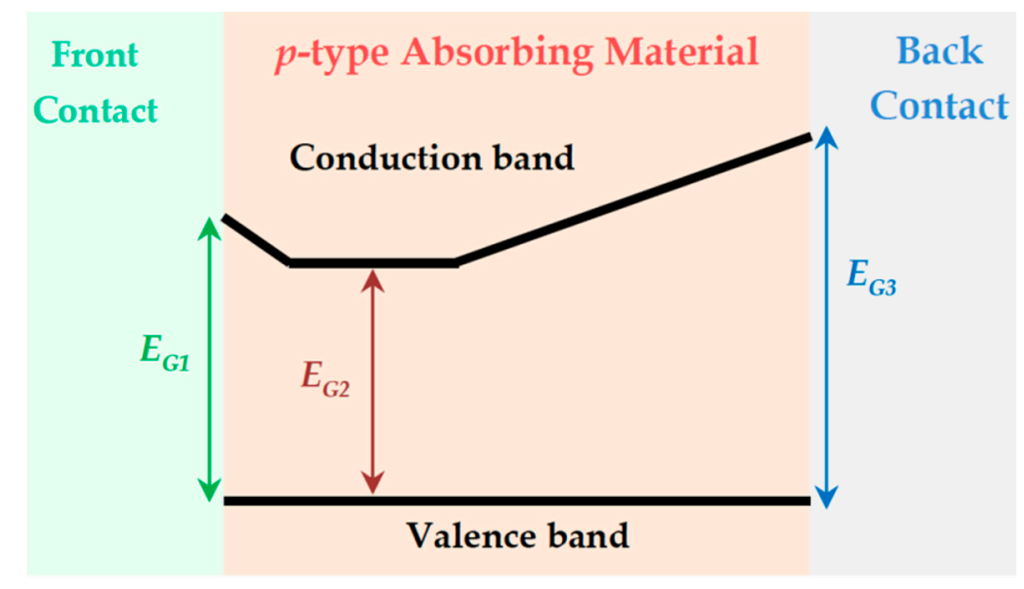

Figure 4. Band diagram of an optimized Ga double-graded CIGS absorber material [9].

Unfortunately, the precursors prepared with the aforementioned procedure that were thought to result in a CIGS absorber layer with enhanced photovoltaic properties did not produce the desired result, as can be seen in the in-depth profile analysis obtained with secondary ion mass spectroscopy (SIMS) (Figure 5).

$\mathrm{Ga}_{2} \mathrm{Se}_{3}$ is not the ideal Ga-based starting material to allow the Ga to react correctly with the other elements because it does not release enough Ga during the reaction of $\mathrm{Cu}$ and In with selenium. As a result, an In-rich absorber layer is obtained instead of a Ga-rich surface layer.

With the aim to produce solar cells of higher performance, the reactivity of the starting materials has to be adjusted to obtain an improved Ga distribution within the absorber layer. To achieve this condition, $\mathrm{In}_{2} \mathrm{Se}_{3}$ and $\mathrm{Ga}_{2} \mathrm{Se}_{3}$ precursors have to be replaced with other materials, which can interact more effectively with one another. For this purpose, $\mathrm{In}_{2} \mathrm{Se}_{3}$ was replaced with InSe, whereas $\mathrm{Ga}_{2} \mathrm{Se}_{3}$ was replaced with GaSe. 


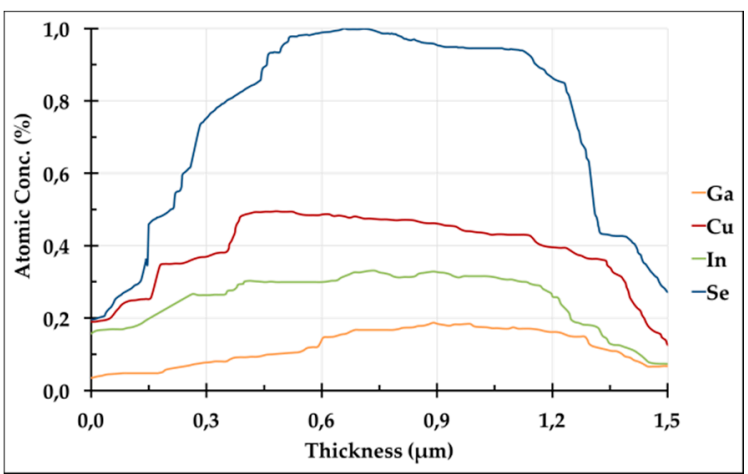

(a)

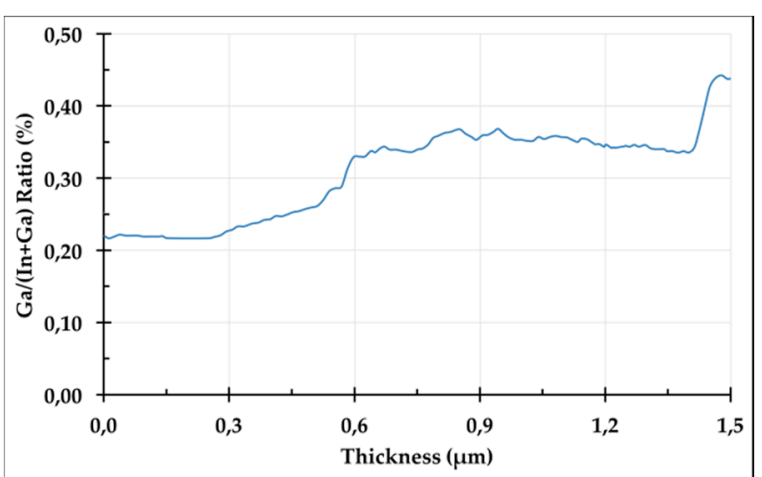

(b)

Figure 5. (a) Secondary ion mass spectroscopy (SINS) in-depth profile spectrum of the CIGS layer, after selenization of $\mathrm{In}_{2} \mathrm{Se}_{3}-\mathrm{Ga}_{2} \mathrm{Se}_{3}-\mathrm{Cu}$ stacked layers. To make the spectrum more legible, the Mo signal was removed; (b) detail of the $\mathrm{Ga} /(\mathrm{In}+\mathrm{Ga})$ ratio along the CIGS layer thickness.

\subsection{The InSe, GaSe, and $\mathrm{Cu}$ System}

By using the process conditions already optimized for the method described above, $\operatorname{In}_{2} \mathrm{Se}_{3}$ was replaced with InSe to obtain a more effective interaction with the other constituents [7,13]. As InSe is more reactive than $\mathrm{In}_{2} \mathrm{Se}_{3}$, it can probably release In into the absorber material in a more uniform way. InSe allows for the formation of a better CIS matrix with the correct stoichiometry on a larger portion of the absorber, enhancing both its optical and electronic properties. The InSe film is deposited at a $670 \mathrm{~K}$ substrate temperature, by RF. magnetron sputtering with a $3.3 \mathrm{~W} / \mathrm{cm}^{2}$ power density discharge, under a $0.5 \mathrm{~Pa}$ argon pressure $(1.2 \mathrm{~nm} / \mathrm{s}$ deposition rate).

As mentioned, $\mathrm{Ga}_{2} \mathrm{Se}_{3}$ was replaced with GaSe. This material exhibits a lower melting point and decomposes at a lower temperature with respect to $\mathrm{Ga}_{2} \mathrm{Se}_{3}$. It could release $\mathrm{Ga}$ atoms more easily, allowing for a better interaction with the other elements, especially with copper. Furthermore, GaSe was found to have a thermal stability similar to that of $\mathrm{Ga}_{2} \mathrm{Se}_{3}$, and uniform and homogeneous polycrystalline GaSe films can be successfully obtained at deposition temperatures that are as low as $670 \mathrm{~K}$. GaSe is deposited by RF magnetron sputtering, with a $1.8 \mathrm{~W} / \mathrm{cm}^{2}$ power density under a $0.5 \mathrm{~Pa}$ argon pressure $(0.3 \mathrm{~nm} / \mathrm{s}$ deposition rate). InSe, GaSe, and $\mathrm{Cu}$ were deposited in sequence as described above (Figure $1 \mathrm{~b}$ ). In this case, $\mathrm{Cu}$ can be sputtered onto GaSe at the same deposition temperature (about $670 \mathrm{~K}$ ) without causing any collateral issues inside the precursor, while improving surface uniformity. The XRD spectra of the as-deposited precursor layers and of the same film after the selenization process are showed in Figure 6a,b respectively [14].

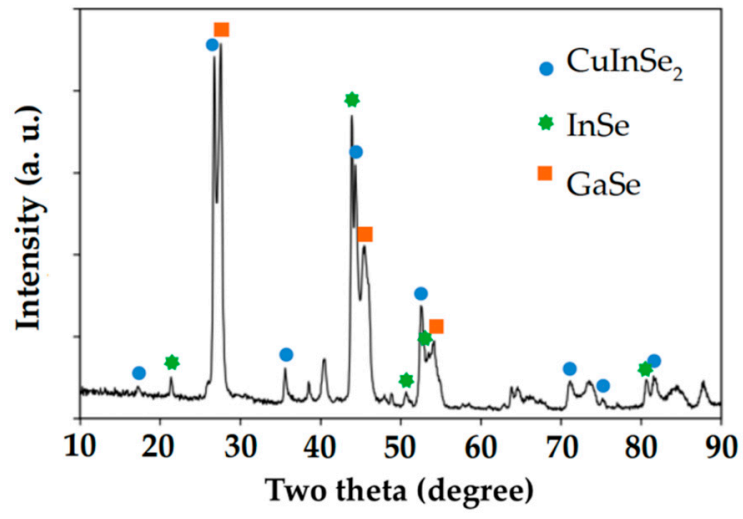

(a)

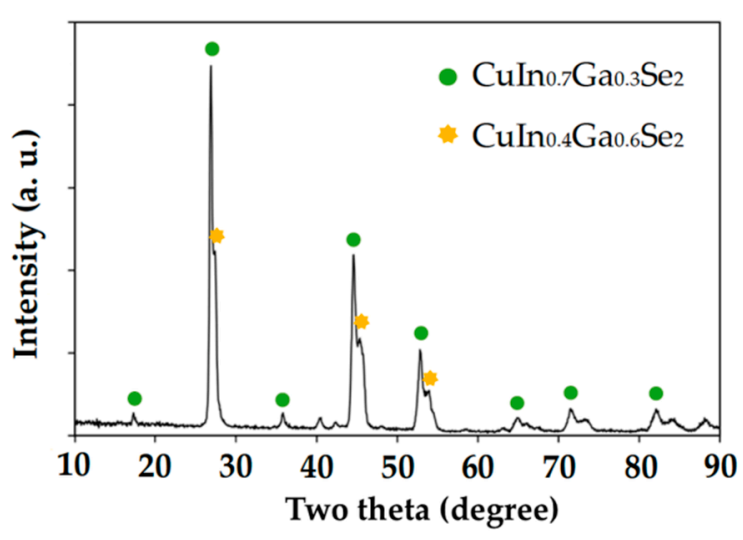

(b)

Figure 6. Grazing incidence XRD spectra of: (a) InSe-GaSe-Cu-based precursor layers and (b) the same sample after selenization. 
SEM images (Figure 7) show the superficial uniformity of the precursor stack and of the absorber layer immediately after the selenization step. This CIGS film is more compact and dense when compared with the CIGS film that was prepared starting with $\mathrm{Ga}_{2} \mathrm{Se}_{3}$ and $\mathrm{In}_{2} \mathrm{Se}_{3}$, and exhibits an average grain size larger than $1 \mu \mathrm{m}$.

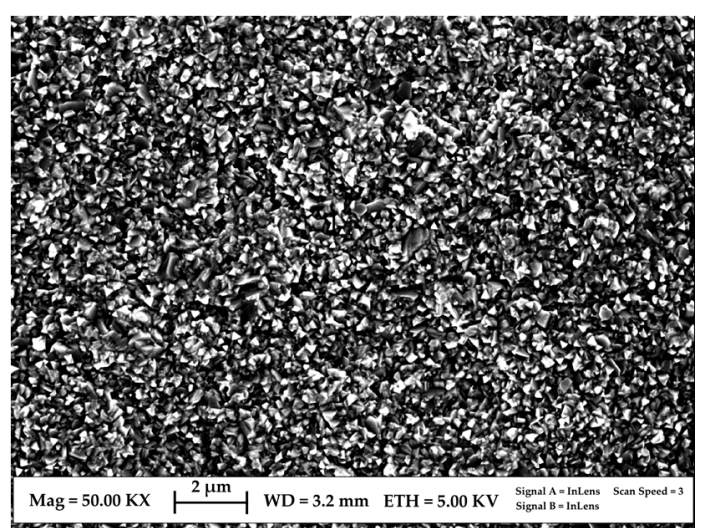

(a)

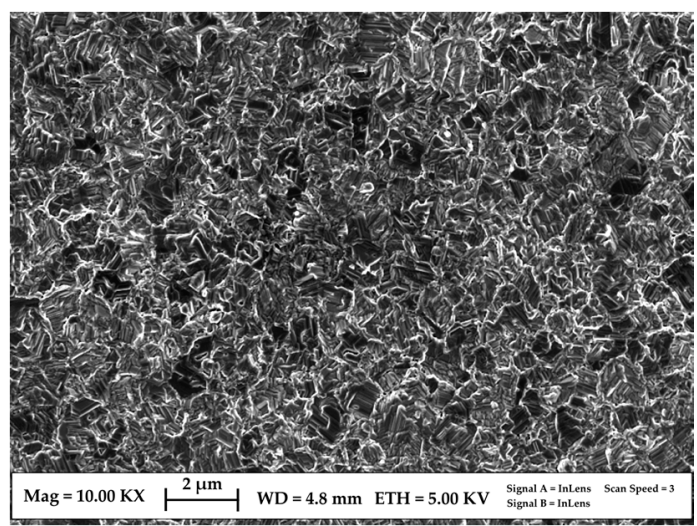

(b)

Figure 7. SEM images of the: (a) morphology of the as-deposited InSe-GaSe-Cu precursor sequence; and (b) the resulting CIGS layer after selenization.

The highest photovoltaic parameters exhibited by solar cells produced with this absorber material are: $\mathrm{V}_{\mathrm{OC}}=560 \mathrm{mV}, \mathrm{JSC}_{\mathrm{SC}}=34.92 \mathrm{~mA} / \mathrm{cm}^{2}, \mathrm{FF}=64 \%$, and $\eta=12.51 \%$. Measurements were performed at standard conditions (J-Vcurve in Figure A1, sample \#3097).

The unexpectedly low values found for $\mathrm{V}_{\mathrm{OC}}$ and FF were attributed to the fact that gallium, which is less reactive than indium, tends to diffuse towards the bottom and ends up being drained away from the film surface.

\subsubsection{The InSe, GaSe, $\mathrm{Cu}$, and GaSe Layers Sequence}

In order to have more gallium near the surface, a change was proposed in the sequence of the layer deposition. The new sequence consists in depositing films of InSe (900 nm), GaSe (150 nm), Cu $(230 \mathrm{~nm})$, and GaSe $(250 \mathrm{~nm})$ again (Figure 1c) on top of the initial Mo layer.

In order to eliminate the influence of individual sputter targets, whose behavior varies based on different choices of procurement, on the physical properties of the sputtered layers (stoichiometry, adhesion, thermal stability, optical and electrical behavior, etc.) the deposition parameters were changed after every target substitution. In other words, the sputtering parameters were not fixed but they were continually adjusted to obtain the desired film deposition, and this operation was carried out for all sputter targets. This was the only way to make sure the precursors films were deposited reproducibly.

The precursors are then selenized in the standard way. An analysis of the in-depth profile, performed with SIMS spectroscopy (Figure 8), shows that this new absorber layer includes more gallium in proximity of the surface. Moving away from the surface, the Ga concentration decreases and then increases again when approaching the back contact. 


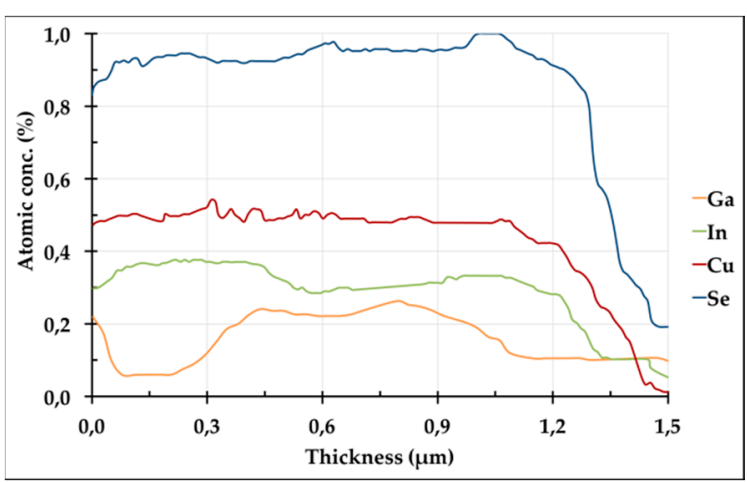

(a)

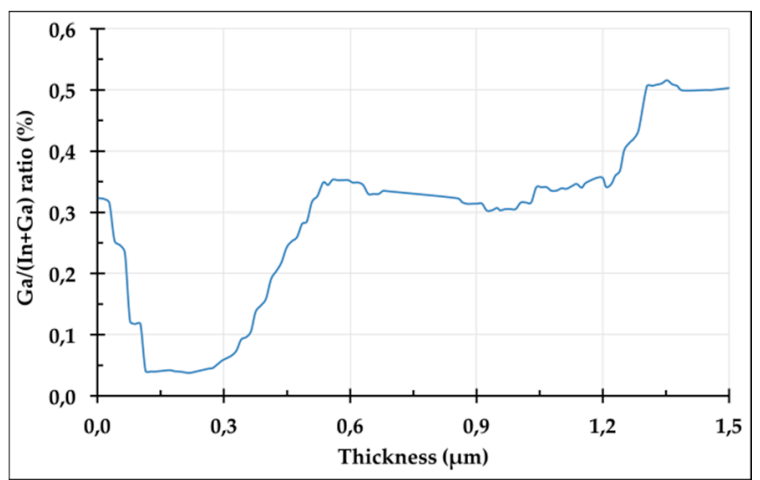

(b)

Figure 8. (a) SIMS in-depth profile spectrum of the CIGS layer after selenization of InSe-GaSe-Cu-GaSe stacked layers. To make the spectrum more legible, the Mo signal was removed; (b) Detail of the $\mathrm{Ga} /(\mathrm{In}+\mathrm{Ga})$ ratio along the CIGS layer thickness.

The highest performing solar cells obtained with this method displayed the following parameters: $\mathrm{V}_{\mathrm{OC}}=576 \mathrm{mV}, \mathrm{J}_{\mathrm{SC}}=38.13 \mathrm{~mA} / \mathrm{cm}^{2}, \mathrm{FF}=0.74$ and $\eta=16.25 \%$. Measurements were carried out in standard conditions (J-V characteristic in Figure A1, sample \#4025) [15].

When the optimized stack of precursor layers (the one with an extra GaSe layer in the third method) is used, an enhanced performance of the solar cells exhibiting energy conversion efficiencies above $15 \%-16 \%$ is reproducibly obtained. This is probably due to the V-shaped Ga distribution, which helps to maximize both the photovoltage and the photocurrent of the solar cell. A good control of the Ga concentration is the key to engineering the profile of the energy gap of the absorbing material, which in turn plays a fundamental role in the operation of a solar cell, as explained in this article's introduction. The detailed analysis of Ga concentration as a function of absorber layer thickness will be the subject of future studies. In particular, the optimization of the thickness of the lower Ga-concentration layer should be addressed in order to maximize the absorbing properties of the CIGS film.

\subsubsection{The Ceramic Substrate}

The ceramic tiles used in this work are covered with glassy enamel which has a composition similar to that of SLG. In this way, the tile surface becomes smoother, making this substrate suitable for thin film deposition. The opaque glassy enamel have typical thicknesses ranging from $300 \mu \mathrm{m}$ up to $1000 \mu \mathrm{m}$. They are deposited starting from wet powders and are processed on the ceramic surface at a temperature between $1210 \mathrm{~K}$ and $1250 \mathrm{~K}$ [16].

The structure of the precursor is composed of a 1500-nm-thick InSe film, a 200-300-nm-thick GaSe film, a 350-400-nm-thick Cu film, and, finally, a 400-500-nm-thick GaSe film as it was for the samples deposited on SLG. All the materials are deposited at a substrate temperature of $670 \mathrm{~K}$, and the precursor is selenized at high temperature $(790 \mathrm{~K})$ in a pure-Se atmosphere. In other words, the process developed on SLG was simply transposed to the ceramic substrate, and the resulting precursor seemed to maintain a morphology of the same quality (Figure 9).

The highest performing solar cells obtained with this method yielded the following parameters: $\mathrm{V}_{\mathrm{OC}}=610 \mathrm{mV}, \mathrm{JSC}=36.79 \mathrm{~mA} / \mathrm{cm}^{2}, \mathrm{FF}=0.61$, and $\eta=13.69 \%$. Measurements were acquired at standard conditions (J-V characteristic in Figure A1, sample \#1113). 


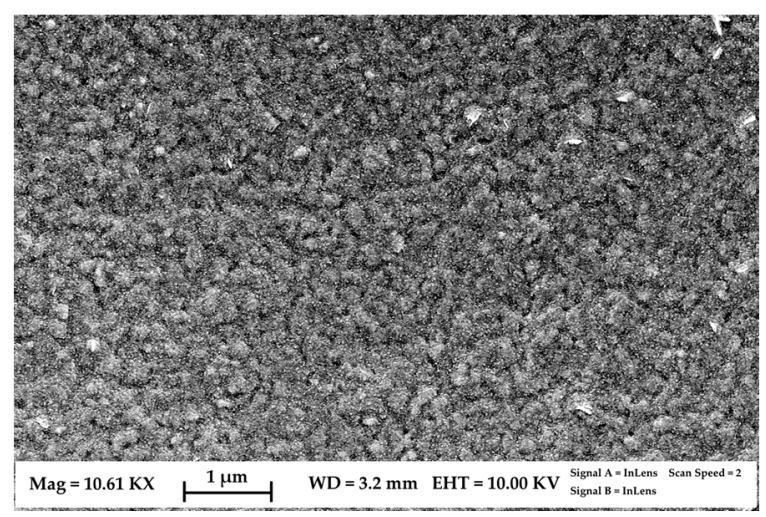

(a)

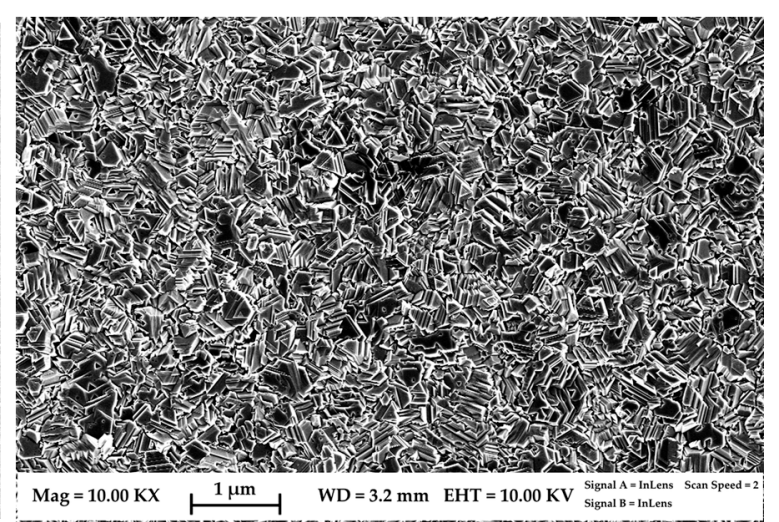

(b)

Figure 9. SEM images showing the morphology of the: (a) precursor made by depositing in sequence InSe-GaSe-Cu-GaSe on ceramic substrate; and (b) same sample after selenization.

All cell parameters refer to an area of around $1 \mathrm{~cm}^{2}$ (if not expressly stated otherwise). The photovoltaic parameters were collected over 20 samples for every method. Each sample included 4 cells; therefore, we tested about 80 cells for each method to make sure that the whole fabrication process was indeed reproducible (as the standard deviation indicates). At any rate, we here reported the PV parameters of solar cells representative of each method. Generally, we have chosen to show the photovoltaic parameters of devices made with layers on which morphological, structural, and compositional investigations were carried out.

As one can see from the data in Table 1, the photocurrent of solar cells grown on ceramic tiles is lower than the photocurrent obtained by solar cells grown on SLG. A possible explanation is that commercially available ceramic tiles are characterized by a high number of macroscopic surface defects. Voids and prominences are larger than the combined thickness of all the deposited films, which cannot fill or cover them completely. If the ceramic surface is covered by glassy enamel, with a composition similar to the SLG, the surface is much smoother, making the ceramic a suitable substrate for a thin-film deposition. The residual defectiveness requires the use of a material poorer in $\mathrm{Cu}$, as compared with CIGS grown on SLG, to avoid a deleterious segregation of binary phases, such as $\mathrm{Cu}_{2} \mathrm{Se}$, inside the surface non-uniformities of the ceramic substrates. A Cu-poor material is obtained by increasing the In concentration. However, this has a negative influence on the Ga-concentration profile as more indium makes it flatter, inevitably leading to a loss of the benefits that come from a V-shape distribution.

Table 1. Comparison between the photovoltaic parameters of $1 \mathrm{~cm}^{2}$ CIGS-based solar cells, fabricated with the different methods on glass and ceramic substrates at the ThiFiLab, whose characteristics are reported in Figure A1. Soda-lime glass: SLG.

\begin{tabular}{|c|c|c|c|c|c|c|c|c|c|}
\hline \multicolumn{4}{|c|}{ Layerthickness (nm) } & \multirow{2}{*}{$\begin{array}{c}\text { Sample } \\
\# 2012\end{array}$} & \multirow{2}{*}{$\begin{array}{c}\text { Substrate } \\
\text { SLG }\end{array}$} & \multirow{2}{*}{$\frac{\mathrm{V}_{\mathrm{OC}}(\mathrm{mV})}{530}$} & \multirow{2}{*}{$\begin{array}{c}\begin{array}{c}\mathrm{JSC} \\
\left(\mathrm{mA} / \mathrm{cm}^{2}\right)\end{array} \\
35.16\end{array}$} & \multirow{2}{*}{$\begin{array}{c}\text { FF (\%) } \\
0.58\end{array}$} & \multirow{2}{*}{$\begin{array}{c}\text { Eta }^{\mathbf{1}}(\mathbf{\%}) \\
10.81\end{array}$} \\
\hline $\begin{array}{c}\mathbf{I n}_{\mathbf{2}} \mathbf{S e}_{3} \\
1000\end{array}$ & & & $\begin{array}{l}\mathrm{Cu} \\
180\end{array}$ & & & & & & \\
\hline $\begin{array}{l}\text { InSe } \\
1000\end{array}$ & & & $\begin{array}{l}\mathrm{Cu} \\
220\end{array}$ & \#3097 & SLG & 560 & 34.92 & 0.64 & 12.51 \\
\hline $\begin{array}{c}\text { InSe } \\
900\end{array}$ & $\begin{array}{c}\text { GaSe } \\
150\end{array}$ & $\begin{array}{c}\mathrm{Cu} \\
230\end{array}$ & $\begin{array}{c}\text { GaSe } \\
250\end{array}$ & $\# 4025$ & SLG & 576 & 38.13 & 0.74 & 16.25 \\
\hline $\begin{array}{c}\text { InSe } \\
1000\end{array}$ & $\begin{array}{c}\text { GaSe } \\
250\end{array}$ & $\begin{array}{l}\mathrm{Cu} \\
350\end{array}$ & $\begin{array}{c}\text { GaSe } \\
450\end{array}$ & \#1113 & Ceramic & 610 & 36.79 & 0.61 & 13.79 \\
\hline
\end{tabular}

${ }^{1}$ Measure performed at $298 \mathrm{~K}$ under $100 \mathrm{~mW} / \mathrm{cm}^{2}$ A.M. 1.5 filtered light (standard conditions). 


\section{Conclusions}

By using RF sputtering for the deposition of chalcogenide precursors and their selenization in a pure Se atmosphere, high-efficiency CIGS-based solar cells were produced. We showed how different compounds were tested as starting materials. We described the process based on $\operatorname{In}_{2} \mathrm{Se}_{3}-\mathrm{Ga}_{2} \mathrm{Se}_{3}$ and its evolution towards the InSe-GaSe system, which granted us better control of the Ga-concentration profile inside the absorber layer. By following this method, a fine-tuning of the absorber material energy gap is achieved, and devices with an efficiency of $15 \%-16 \%$ were assembled on SLG. This process can also be extended to ceramic substrates and leads to the production of PV tiles with efficiencies in the range of $13 \%-14 \%$, which are particularly suitable for the fabrication of ventilated walls in near-zero-energy buildings. Moreover, this process can be easily transposed to flexible thin-film solar cells using flexible thin metal sheets as a substrate. By using simple deposition techniques for all the materials constituting the solar cell, this process could be easily scaled up to the industrial level.

Author Contributions: Alessio Bosio: growth, deposition, and selenization equipment design and installation, sputtering target preparation, project coordination; Greta Rosa and Daniele Menossi: sputtering deposition and materials characterization, device modeling and processing; Nicola Romeo: electrical characterization, lab coordination. All together: critical interpretation of the measurement results.

Conflicts of Interest: The authors declare no conflict of interest.

\section{Appendix A}

This figure summarizes the results obtained with absorber layers realized by using different precursor stacked layers. It highlights the conclusive meaning of the results.

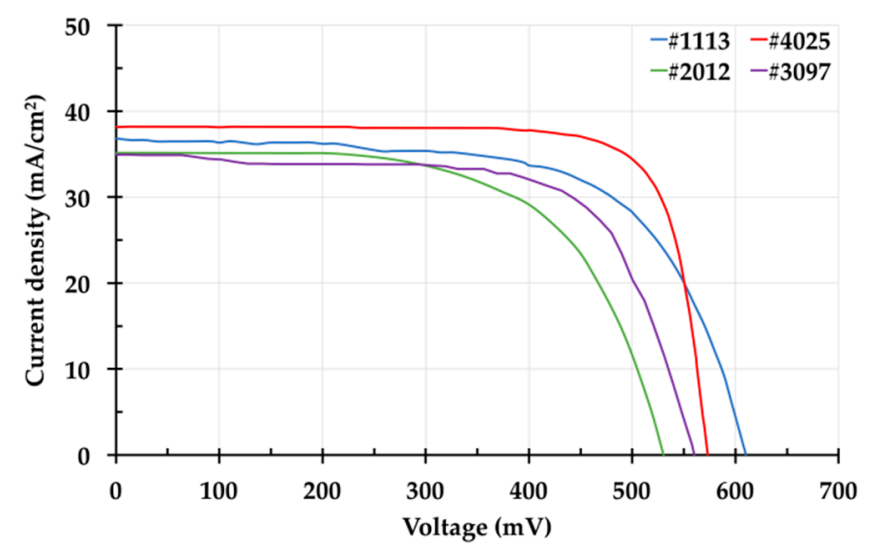

Figure A1. Comparison between the J-V characteristics of four different solar cells all grown on a SLG substrate, except for the CIGS film. \#1113: grown on a ceramic substrate; \#2012: first method- $\left(\mathrm{In}_{2} \mathrm{Se}_{3}-\mathrm{Ga}_{2} \mathrm{Se}_{3}-\mathrm{Cu}\right)$; \#3097: second method-(InSe-GaSe-Cu); \#4025: third method-(InSe-GaSe-Cu-GaSe); \#1113: third method-(InSe-GaSe-Cu-GaSe). Measurement performed at $298 \mathrm{~K}$ under $100 \mathrm{~mW} / \mathrm{cm}^{2}$ air mass (A.M.) 1.5 filtered light (standard conditions).

\section{References}

1. Solar Power Europe-Global Market Outlook for Solar Power 2015-2019. Available online: http:/ /www. solarpowereurope.org/home/ (accessed on 12 January 2016).

2. Bube, R.B. Copper Indium Diselenide And Other I-III-VI Materials. In Photovoltaic Materials, 1st ed.; Newman, R.C., Ed.; Imperial College Press: London, UK, 1998; Volume 1, pp. 184-214.

3. Kessler, F.; Herrmann, D.; Powalla, M. Approaches to flexible CIGS thin-film solar cells. Thin Solid Films 2004, 480-481, 491-498. [CrossRef] 
4. Reinhard, P.; Chirila, A.; Blosch, P.; Pianezzi, F.; Nishiwaki, S.; Buechelers, S.; Tiwari, A.N. Review of progress toward $20 \%$ efficiency flexible CIGS solar cells and manufacturing issues of solar modules. IEEE J. Photovolt. 2013, 3, 572-580. [CrossRef]

5. Solar Frontier Hits $22.3 \%$ on CIGS Cell. Available online: http://www.pv-magazine.com/news/details / beitrag/solar-frontier-hits-223-on-cigs-cell_100022342/\#axzz3weK2S0hj (accessed on 8 January 2016).

6. Romeo, N.; Bosio, A.; Mazzamuto, S.; Menossi, D.; Romeo, A. CIGS thin films prepared by sputtering and selenization by using $\mathrm{In}_{2} \mathrm{Se}_{3}, \mathrm{Ga}_{2} \mathrm{Se}_{3}$ and $\mathrm{Cu}$ as sputtering targets. In Proceedings of the 35th IEEE Photovoltaic Specialists Conference (PVSC), Honolulu, HI, USA, 20-25 June 2010; pp. 786-788.

7. Menossi, D.; Bosio, A.; Romeo, N. Fabrication of a $\mathrm{Cu}(\mathrm{In}, \mathrm{Ga}) \mathrm{Se}_{2} / \mathrm{CdS}$ thin-film solar cell. In Key Developments in CuInGaSe, Thin Film Solar Cell, 1st ed.; LAP Lambert Academic Publishing: Saarbrücken, Germany, 2014; pp. 39-84.

8. Gloeckler, M.; Sites, J.R. Band-gap grading in $\mathrm{Cu}(\mathrm{In}, \mathrm{Ga}) \mathrm{Se}_{2}$ solar cells. J. Phys. Chem. Solids 2015, 66, 1891-1894. [CrossRef]

9. Contreras, M.A.; Tuttle, J.; Gabor, A.M.; Tennant, A.; Ramannathan, K.; Asher, S.; Franz, A.; Keane, J.; Wang, L.; Scofield, J.; et al. High efficiency $\mathrm{Cu}(\mathrm{In}, \mathrm{Ga}) \mathrm{Se}_{2}$-based solar cells: Processing of novel absorber structures. In Proceedings of the Conference Record of the IEEE Photovoltaic Specialists Conference, New Orleans, LA, USA, 19-24 May 2002. [CrossRef]

10. Gorji, N.E.; Perez, M.D.; Reggiani, U.; Sandrolini, L. A New Approach to Valence and Conduction Band Grading in CIGS Thin Film Solar Cells. Int. Assoc. Comput. Sci. Inf. Technol. 2012, 4, 573-576. [CrossRef]

11. Dullweber, T.; Rau, U.; Contreras, M.A.; Noufi, R.; Schock, H. Photogeneration and carrier recombination in graded gap Cu(In,Ga)Se 2 solar cells. IEEE Trans. Electron Dev. 2000, 47, 2249-2254.

12. Romeo, N.; Bosio, A.; Menossi, D.; Catellani, C.; Dharmadasa, R.; Romeo, A. High efficiency $\mathrm{Cu}(\mathrm{In}, \mathrm{Ga}) \mathrm{Se}_{2} / \mathrm{CdS}$ thin-film solar cells obtained with precursors sputtered from InSe, GaSe and Cu targets. Thin Solid Films 2013, 535, 88-91. [CrossRef]

13. Chirilă, A.; Buecheler, S.; Pianezzi, F.; Bloesch, P.; Gretener, C.; Uhl, A.R.; Fella, C.; Kranz, L.; Perrenoud, J.; Seyrling, S.; et al. Highly efficient $\mathrm{Cu}(\mathrm{In}, \mathrm{Ga}) \mathrm{Se}_{2}$ solar cells grown on flexible polymer films. Nat. Mater. 2011, 10, 857-861. [CrossRef] [PubMed]

14. Bosio, A.; Menossi, D.; Romeo, A.; Romeo, N. Polycrystalline Cu(InGa)Se 2 /CdS Thin Film Solar Cells Made by New Precursors. In Solar Cells Research and Application Perspectives, 1st ed.; Morales-Acevedo, A., Ed.; InTech: Rijeka, Croatia, 2013; pp. 79-106.

15. Bosio, A.; Menossi, D.; Rosa, G. I risultati sperimentali. In Il Fotovoltaico di Seconda Generazione Diventa Competitivo, 1st ed.; Aracne Editrice: Rome, Italy, 2015; pp. 169-189.

16. Bosio, A.; Menossi, D.; Rosa, G.; Romeo, N. Key developments in CIGS thin-film solar cells on ceramic substrates. Cryst. Res. Technol. 2014, 49, 620-627. [CrossRef] 